This is an open access article under the CC-BY-SA license (https://creativecommons.org/licenses/by-sa/4.0/) ISSN 2355-6102 (print), ISSN 2502-0404 (online)

\title{
STATUS MUTU AIR SUNGAI CIKANIKI KABUPATEN BOGOR BERDASARKAN INDEKS PENCEMARAN DAN KEANEKARAGAMAN MAKROFAUNA
}

\author{
${ }^{1}$ Mia Azizah, ${ }^{2}$ Nengsih Anen \\ ${ }^{1)}$ Progam Studi Biologi FMIPA Universitas Nusa Bangsa Bogor \\ ${ }^{2)}$ Program Studi Kehutanan Universitas Nusa Bangsa Bogor \\ Author correspondent : miaazizah@unb.ac.id
}

\section{Diterima 29 Agustus 2019 disetujui 5 Oktober 2019}

\begin{abstract}
Cikaniki is a river that originates in the Mount Halimun Salak National Park (TNGHS) located in Bogor Regency. It was chosen as a research location because, along with the Cikaniki river flow, compounds from residential and industrial that use cyanide and mercury for gold ore extraction. Research carried out during March - June 2019. The purpose of this research is to 1) Analyze the condition of Cikaniki river based on macrofauna as a bioindicator, 2) Analyze the value of Cikaniki river pollution index; 3) To know the correlation between Macrofauna abundance with the pollution index value. The selection of observation stations chosen (purposive sampling) based on the consideration of the representation of the state of the waters. Analyze water quality status is carried out using the pollution index method which has been considered comprehensive according to the Decree of the Minister of Environment of the Republic of Indonesia Number 115 of 2003. The results of the study indicate the status of water quality in the Cikaniki River at all stations is mildly polluted.
\end{abstract}

Keywords: river water quality status, pollution index, Cikaniki river

\section{PENDAHULUAN}

Ekosistem sungai merupakan habitat bagi beragam biota air yang keberadaannya sangat dipengaruhi oleh lingkungan sekitarnya. Organisme tersebut diantarnya tumbuhan air, seperti ikan, krustacea, gastropoda, bentos serta plankton dan perifiton. Salah satu komponen biotik yang representatif adalah makrofauna, makrofauna sebagai organisme yang hidup di perairan sangat peka terhadap perubahan kualitas air tempat hidupnya. Perubahan lingkungan perairan contohnya di Daerah Aliran Sungai (DAS) berpengaruh terhadap komposisi dan keragaman populasi kelas tersebut (Putri,2017). Hal ini dikarenakan makrofauna adalah hewan yang berukuran lebih dari (Effendi,2003)dari $10 \mathrm{~mm}$ dan dapat terlihat langsung oleh mata tanpa harus menggunakan alat pembesar (lup atau mikroskop) (Odum,1993). Penurunan kualitas air akan menurunkan kekayaan sumber daya alam perairan tersebut. Adanya benda-benda asing yang mengakibatkan air tersebut tidak dapat digunakan sesuai dengan peruntukkannya secara normal disebut dengan pencemaran air. Akibat adanya pencemaran merkuri pada proses amalgamasi emas dengan menggunakan merkuri tersebut, konsentrasi merkuri di beberapa wilayah di Sungai Cikaniki melebihi kriteria konsentrasi merkuri yang aman bagi lingkungan perairan (Yoga, 2014). Salah satu cara untuk mengidentifikasi kondisi perairan di Kabupaten Bogor adalah dengan menggunakan metode Indeks Pencemaran. Metode indeks pencemaran dianggap komprehensif untuk penentuan kualitas air (Sheftiana et.al, 2017), namun sampai dengan saat ini penelitian mengenai identifikasi kualitas perairan dengan metode Indeks Pencemaran masih jarang digunakan khususnya di wilayah perairan Kabupaten Bogor. Penelitian ini menjelaskan tentang persebaran makrofauna sebagai indikator Biologi sebagai penentu kualitas perairan, serta nilai indeks pencemarannya terhadap parameter-parameter yang diukur. 
Identifikasi kerusakan air sungai akibat pencemaran merupakan salah satu upaya guna menjaga kelestarian lingkungan perairan, selain itu dapat dijadikan referensi terkait pemanfaatan sungai yang memiliki potensi pariwisata. Hasil analisa data dari penelitian ini berupa informasi dan data komprehensif yang dapat dijadikan salah satu referensi rekomendasi dalam pengembangan dan pembangunan ekosistem perairan tawar khususnya daerah aliran sungai.

Tujuan dari penelitian ini adalah untuk 1) Menganalisis kondisi sungai Cikaniki berdasarkan bioindikator makrofauna, 2) Menganalisis nilai indeks pencemaran sungai Cikaniki 3) Mengetahui korelasi antara Kelimpahan Makrofauna dengan nilai indeks pencemaran sungai Cikaniki. Dalam penelitian ini, DAS Cikaniki dipilih sebagai lokasi penelitian dikarenakan perkembangannya yang pesat terutama dalam penggunaan lahan untuk kepentingan industri maupun pemukiman, dibagian hulu sungai terdapat industri emas resmi. Dengan perkembangan itu, dikhawatirkan wilayah perairan Kabupaten Bogor akan tercemari.

\section{METODE}

Penelitian ini dilakukan di sungai Cikaniki pada daerah hulu, tengah dan hilir yangterletak di Kecamatan Nanggung, Kabupaten Bogor dengan menggunakan metode PurposiveSampling dan analisis data secara deskriptif. Pengamatan dilakukan pada 5 titik lokasi yang mewakili anak-anak sungai dan Sungai Cikaniki (Gambar 1). Kawasan ini merupakan bagian dari DAS Cisadane segmen hulu sungai. Identifikasi dilakukan di Laboratorium Biologi, Fakultas Matematika dan Ilmu Pengetahuan Alam, Universitas Nusa Bangsa.

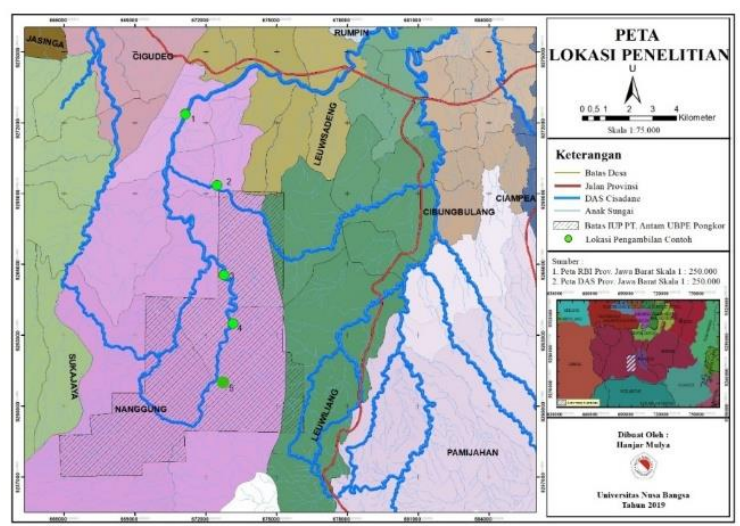

\section{Bahan dan Alat}

Bahan-bahan yang digunakan dalam penelitian ini yaitu, Makrofauna yang ditemukan, Formalin $10 \%$. Dalam penelitian ini alat yang digunakan adalah Electric Fishing, Jala Surber, Jala Tebar, Cooler Box, kamera, kandungan oksigen (Dissolved oxygen) diukur menggunakan DO meter, $\mathrm{pH}$ dan temperatur diukur dengan menggunakan $\mathrm{pH}$ digital meter, kecerahan diukur dengan menggunakan secchi disk.

\section{Pelaksanaan Penelitian Penentuan titik Sampling}

Penentuan titik sampling penelitian menggunakan metode Purposive Sampling dengan pemilihan lokasi di bagian Hulu, Tengah dan Hilir Sungai Cikaniki, penandaan titik sampling menggunakan GPS. Pengambilan sampel dilakukan di 5 titik dengan masing - masing titik dilakukan 3 kali pengulangan pengambilan sampel. Pengambilan sampel dilakukan pada 5 stasiun pengamatan. Stasiun 1 daerah hulu Sungai Cikaniki yang belum dialiri limbah hasil tambang. Stasiun 2, badan sungai tempat beraktivitasnya Penambang Emas Tanpa Izin (PETI) yang menghasilkan limbah merkuri. Stasiun 3, badan sungai yang dialiri limbah hasil tambang dari PT. Antam yang berupa sianida. Stasiun 4, badan sungai yang digunakan sebagai saluran irigasi oleh penduduk. Stasiun 5, merupakan daerah hilir, saluran pembuangan limbah domestik. 


\section{Sampling Makrofauna}

Pengambilan sampel makrofauna di Sungai dan anak sungai Cikaniki yang memiliki tipe aliran arus deras, dangkal, dan berbatu menggunakan menggunakan electric fisher (EF). Pada setiap stasiun pengamatan, dilakukan pengambilan sampel sebanyak tiga kali dari pinggir sungai sampai ke sampai ke seberang sungai. Selain menggunakan electric fishing, pengambilan sampel makrofauna juga meggunakan jala tebar berdiameter 1 $\mathrm{cm}$ dengan ukuran $30 \times 30 \mathrm{~cm}^{2}$ dan jaring ikan berdiameter $1 \mathrm{~mm}$. Pengambilan sampel secara horizontal sebanyak tiga kali ulangan pada masing-masing titik dengan luasan transek sekitar $2 \mathrm{~m}^{2}$, jala tebar diletakan berlawanan arus agar makrofauna dapat tertangkap di alat tersebut. Sampel ikan, krustacea, benthos dan makrofauna lainnya diseleksi dan dimasukkan kedalam kantong plastik $2 \mathrm{~kg}$ yang telah diberi label untuk penomoran, waktu, alat pengambilan sampel dan lokasi pengambilan. Sampel kemudian diawetkan menggunakan Formalin $4 \%$ dan dibawa ke Laboratorium Biologi Universitas Nusa Bangsa untuk diidentifikasi dengan menggunakan beberapa buku identifikasi rujukan(Kottelat (1989) dan Pennak (1993)

\section{Pengambilan Sampel Kualitas Air}

Pengambilan sampel kualitas air dilakukan pada saat pagi, siang dan sore hari sekitar pukul 09.00 sampai dengan 15.00 WIB. Sampel diambil menggunakan metode Grab (Sesaat), yakni dengan cara mengambil 3 sampel secara horizontal dari pinggir sungai pengulangan sebanyak 500 ml dalam satu titik lalu dikomposit dan displit menjadi satu sampel, kemudian dimasukkan kedalam botol polietilen 500 $\mathrm{ml}$, selanjutnya sampel dimasukkan kedalam coolbox. Sampel komposit merupakan sampel campuran dari beberapa waktu pengamatan agar dapat mewakili lokasi penelitian, kemudian sampel dimasukkan ke dalam cool box yang telah terisi es dan dibawa menuju Laboratorium. Pengukuran Parameter DO, pH, kecerahan dan temperatur dilakukan di lapangan.
Biological Oxygen Demand (BOD) diukur berdasarkan, dan Nitrat. Padatan Tersuspensi Total (Total Suspended Solid) diukur berdasarkan metode tentang Cara uji padatan tersuspensi total (Total Suspended Solid, TSS) secara gravimetri. Ammonia diukur dengan menggunakan metode tentang Cara uji kadar amonia dengan spektrofotometer secara fenat, Analisis Total-Fosfat berdasarkan metode.

\section{Indeks pencemaran}

Pengelolaan kualitas air atas dasar Indeks Pencemaran (IP) yang digunakan dapat memberi masukan pada pengambil keputusan agar dapat menilai kualitas badan air untuk suatu peruntukan serta melakukan tindakan untuk memperbaiki kualitas jika terjadi penurunan kualitas akibat kehadiran senyawa pencemar. Penentuan status pencemaran ditentukan dengan menggunakan indeks pencemaran persamaan 1 berdasarkanKeputusan Menteri Negara Lingkungan Hidup Nomor 115 Tahun 2003sebagaimanaberikut:

$$
\begin{aligned}
& \qquad I P_{j}=\sqrt{\frac{\left(C_{i} / L_{i j}\right)_{M}^{2}+\left(C_{i} / L_{i j}\right)_{R}^{2}}{2}} \\
& \cdot \mathrm{Pj}=\text { indeks pencemaran bagi peruntukan } \mathrm{j}, \\
& \cdot \mathrm{Ci}=\text { konsentrasi parameter kualitas air } \mathrm{i}, \\
& \cdot \mathrm{Lij}=\text { konsentrasi parameter kualitas air i yang tercantum dalam baku peruntukan air } \mathrm{j}, \\
& \cdot \mathrm{M}=\text { maksimum, } \mathrm{R}=\text { rerata. }
\end{aligned}
$$

Indeks kualitas air IP ditentukan dari result nilai maksimum dan nilai rerata rasio konsentrasi perparamater terhadap nilai baku mutunya. Kelas indeks IP ada 4 dengan skor $0 \leq \mathrm{PIj} \leq 1,0$ adalah 1. $0 \leq \mathrm{PIj} \leq 1,0$ : Memenuhi baku mutu (kondisi baik)

2. $1,0<\operatorname{PIj} \leq 5,0$ : Tercemar ringan

3. $5,0<\mathrm{PIj} \leq 10$ : Tercemar sedang

4. $\mathrm{PIj}>10:$ Tercemar berat

\section{HASIL DAN PEMBAHASAN Keanekaragaman Jenis Makrofauna}

Selama dilakukannya penelitian, total ikan yang berhasil dikumpulkan berjumlah 135 ekor. Hasil identifikasi menunjukan adanya 7 spesies dari 7 famili yang berhasil dikumpulkan (Tabel 1). Jumlah tersebut 
dari tiga stasiun pengamatan masing- masing

adalah

Tabel 1.Keanekaragaman Jenis Ikan di Sungai Cikaniki

\begin{tabular}{|c|c|c|c|c|c|c|c|c|c|c|}
\hline \multirow[b]{2}{*}{ No } & \multirow[b]{2}{*}{ Family } & \multirow[b]{2}{*}{ Spesies } & \multirow[b]{2}{*}{$\begin{array}{l}\text { Nama } \\
\text { Lokal }\end{array}$} & \multirow[b]{2}{*}{$\begin{array}{l}\text { Status } \\
\text { IUCN }\end{array}$} & \multicolumn{5}{|c|}{ Stasiun } & \multirow[b]{2}{*}{ Jumlah } \\
\hline & & & & & $\begin{array}{c}\mathrm{St} \\
1\end{array}$ & $\begin{array}{l}\mathrm{St} \\
2\end{array}$ & $\begin{array}{c}\mathrm{St} \\
3\end{array}$ & $\begin{array}{c}\mathrm{St} \\
4\end{array}$ & $\begin{array}{c}\mathrm{St} \\
5\end{array}$ & \\
\hline 1 & Balitoridae & $\begin{array}{l}\text { Nemacheilus } \\
\text { chrysolaimos }\end{array}$ & $\begin{array}{l}\text { Jeler } \\
\text { kecil }\end{array}$ & $\begin{array}{l}\text { belum } \\
\text { dievaluas } \\
\text { i } \\
\text { beresiko }\end{array}$ & 3 & 15 & 20 & 6 & 6 & 50 \\
\hline 2 & Cyprinidae & Puntius binotatus & Benteur & $\begin{array}{l}\text { rendah } \\
\text { belum }\end{array}$ & 4 & 14 & 13 & 10 & 3 & 44 \\
\hline 3 & Sisoridae & $\begin{array}{l}\text { Glyptothorax } \\
\text { platypogon ides }\end{array}$ & Kehkel & $\begin{array}{l}\text { dievaluas } \\
\mathrm{i}\end{array}$ & 1 & 1 & 4 & 4 & 3 & 13 \\
\hline 4 & Channidae & Channa striata & Gabus & $\begin{array}{l}\text { beresiko } \\
\text { rendah } \\
\text { beresiko }\end{array}$ & 4 & 1 & 3 & 2 & 2 & 12 \\
\hline 5 & Clariidae & Clarias batrachus & Lele & $\begin{array}{l}\text { rendah } \\
\text { belum }\end{array}$ & & & 8 & 1 & & 9 \\
\hline 6 & Poecillidae & Poecilia reticulata & $\begin{array}{l}\text { Bungkre } \\
\text { ung }\end{array}$ & $\begin{array}{l}\text { dievaluas } \\
\mathrm{i} \\
\text { beresiko }\end{array}$ & 3 & & 1 & & & 4 \\
\hline 7 & Synbranchidae & Monopterus albus & Belut & rendah & 1 & & 1 & & 1 & 3 \\
\hline & Jumlah Individu & & & & 16 & 31 & 50 & 23 & 15 & 135 \\
\hline
\end{tabular}

*Keterangan: St $1:$ Hulu, St 2 : Aktivitas PETI, St $3:$ Aktivitas PT. Antam, St 4: Saluran Irigasi, St $5:$ Hilir

Stasiun pengamatan 3 menjadi tempat yang paling banyak didapatkan jumlah dan jenis ikan. Hal ini diduga berhubungan dengan kondisi stasiun pengamatan 3 yang sudah jauh dari kegiatan penambangan, dekat dengan pemukiman dan terdapat persawahan sehingga memungkinkan persediaan makanan menjadi melimpah. Total jumlah individu terbanyak yang berhasil dikumpulkan di sungai Cikaniki sepanjang konsesi tambang emas pongkor adalah jenis Nemacheilus chrysolaimos dari famili Balitoridae sebanyak 50 ekor. Diikuti oleh jenis Puntius binotatus dari famili Cyprinidae dengan jumlah 44 ekor. Lalu jenis Glyptothorax platypogonides dari famili Sisoridae berjumlah 13 ekor. Spesies Monopterus albus merupakan spesies dengan jumlah paling sedikit yangditemukan di sepanjang aliran sungai $\begin{array}{llll}\text { Cikaniki yaitu } 3 & \text { spesies. }\end{array}$

Tabel 2. Indeks Keanekaragaman, Indeks Kemerataan dan Indeks Dominansi tiap stasiun

\begin{tabular}{llccc}
\hline NO & Stasiun & $\mathrm{H}^{\prime}$ & $\mathrm{E}$ & $\mathrm{C}$ \\
\hline 1 & Hulu & 1,67 & 0,93 & 0,20 \\
2 & Aktivitas PETI & 0,93 & 0,52 & 0,44 \\
3 & Aktivitas PT. ANTAM & 1,53 & 1,58 & 0,26 \\
4 & Saluran Irigasi & 1,36 & 0,71 & 0,29 \\
5 & Hilir & 1,45 & 1,83 & 0,26 \\
\hline
\end{tabular}

Hasil pengamatan di lapangan dan identifikasi di Laboratorium didapatkan 7 jenis spesies Ikan yang terbagi kedalam 7 family di sepanjang aliran sungai Cikaniki (Tabel 1), jumlah yang ditemukan lebih sedikit dibandingkan hasil penelitian Ridho (2003). Menurut Wahyuni (2018) adanya penurunan jumlah Ikan dapat disebabkan adanya kerusakan habitat diantaranya berkaitan dengan peningkatan jumlah 
penduduk, kegiatan industri, perubahan tataguna dan pengelolaan lahan, kebijakan ekonomi dalam pembangunan, serta tingkat kemiskinan yang tinggi. Hasil penelitian secara keseluruhan komposisi jenis ikan yang ditemukan di Sungai Cikaniki pada stasiun 3 lebih beragam dibandingkan dengan stasiun lainnya. Jumlah ikan di stasiun 1 (16 individu), Stasiun 2 terdapat 31 individu, Jumlah ikan yang tertangkap distasiun 3 sebanyak 50 individu terdiri dari 7 spesies dan 7 famili, stasiun 4 (23 individu) dan pada stasiun 5 hanya terdapat 15 individu. Stasiun 1 dan stasiun 5 yang merupakan daerah hulu dan hilir jumlah spesies ikan yang tertangkap paling sedikit dibandingkan dengan stasiun lainnya hal ini dapat disebabkan stasiun 1 telah mengalami deforestasi karena adanya aktivitas penambangan, dan stasiun 5 mendapat tekanan dari aktivitas penduduk didaerah hilir. Jumlah jenis ikan di stasiun 2 dan stasiun 3 yang merupakan kawasan pertambangan Pertambangan Liar (PETI) dan PT. ANTAM memiliki komposisi jenis yang lebih banyak dibandingkan dengan stasiun lainnya, diduga karena daerah tersebut masih alami dengan vegetasi hutan lebat sehingga memiliki kompleksitas struktur habitat yang lebih tinggi. Kompleksitas struktur habitat dapat mempertahankan kekayaan jenis yang tinggi, karena memiliki heterogenitas habitat yang lebih besar (Sulistyarto et al 2007).

Dari hasil tangkapan selama penelitian ditemukan Nemacheilus chrysolaimos,Puntius binotatus, Glyptothorax platypogonides,Channa striata, Clarias batracus, Monopterus albus merupakan ikan spesies asli Indonesia. Sedangkan spesies Poecilia reticulata merupakan ikan introduksi yang berasal dari Amerika Serikat, yaitu Venezuela, Barbados,

Trinidad, Brazil (Rachmatika, 1998). Nemacheilus chrysolaimos hidup di sungaisungai kecil yang jernih dan beraliran deras, dengan substrat berupa pasir atau batu kerikil. Mangsanya di antaranya adalah tempayak lalat(Diptera) dan Trichoptera. Ikan yang mendominasi menandakan jenis ikan tersebut dapat bertahan hidup dan dapat beradaptasi dengan baik terhadap kondisi sungai di sungai Cikaniki. Bentuk mulut ikan juga mempengaruhi preferansi habitat atau pembagian relung ekologi dan perbedaan dalam cara atau teknik mendapatkan makanannya. Puntius binotatus merupakan anggota dari Suku Cyprinidae dengan ciri khasnya adalah bahwa pada sisik terdapat proyeksi dari pusat ke pinggir seperti jari - jari pada roda, jari-jari yang ke arah samping tidak melengkung ke arah belakang; ikan muda dan kadang-kadang dewasa memiliki 2- 4 bintik bulat sampai lonjong di tengah badan (Kottelat et a.l, 1993). Perubahan kondisi lingkungan juga mempengaruhi perubahan persediaan makanan dan akan merubah perilaku makan ikan (Zahid, 2008). Menurut Samuel dan Adjie (2008) Cyprinidae merupakan ikan penghuni air tawar terbanyak yang dapat ditemukan diberbagai kondisi lingkungan.

\section{Status Mutu Air Sungai Cikaniki Berdasarkan Indeks Pencemaran}

Data yang diperoleh merupakan hasil dari pengukuran langsung dilapangan (Suhu, $\mathrm{pH}$, TDS) dan Pengukuran di Laboratorium (Nitrat, Ammonia, Fosfat, BOD, COD, DO, TSS dan TSS) (Tabel 3). 
Tabel 3. Nilai Faktor Lingkungan Aliran Sungai Cikaniki

\begin{tabular}{llrccccc}
\hline No & Faktor Lingkungan & Hulu & PETI & PT. ANTAM & Irigasi & Hilir & $\begin{array}{c}\text { Baku } \\
\text { Mutu }\end{array}$ \\
\hline 1. & Suhu $\left({ }^{\circ} \mathrm{C}\right)$ & 27 & 27,5 & 31 & 32 & 30 & \pm 30 \\
2. & $\mathrm{pH}$ & 7,5 & 7,3 & 7,7 & 7,3 & 7,4 & $6-9$ \\
3. & Nitrat $(\mathrm{mg} / \mathrm{L})$ & 0,6 & 0,6 & 1,8 & 1 & 0,5 & 10 \\
4. & Ammonia $(\mathrm{mg} / \mathrm{L})$ & 0,02 & 0,02 & 0,03 & 0,01 & 0,02 & 0,5 \\
5. & Fosfat $(\mathrm{mg} / \mathrm{L})$ & 0,02 & 0,04 & 0,03 & 0,03 & 0,01 & 0,2 \\
6. & BOD $(\mathrm{mg} / \mathrm{L})$ & 3,95 & 3,33 & 2,29 & 4,78 & 3,33 & 2 \\
7. & COD $(\mathrm{mg} / \mathrm{L})$ & 29,9 & 27,8 & 28,1 & 39,8 & 27,8 & 10 \\
8. & DO $(\mathrm{mg} / \mathrm{L})$ & 9,1 & 10,4 & 10 & 10 & 8,8 & 6 \\
9. & Total suspended solid $(\mathrm{mg} / \mathrm{L})$ & 18 & 17 & 13,3 & 19,7 & 10,7 & 50 \\
10. & Total Disolved Solids $(\mathrm{mg} / \mathrm{L})$ & 23 & 26 & 319 & 33 & 37 & 1000 \\
\hline
\end{tabular}

a. $\mathrm{pH}$ fitoplankton dalam proses fotosintetis.

Menurut Peraturan Pemerintah Republik Indonesia No. 82 tahun 2001 angka $\mathrm{pH}$ yang didapat selama penelitian berada pada kondisi optimum, yaitu 6-9. $\mathrm{pH}$ mempengaruhi toksisitas suatu senyawa kimia. pH pada stasiun pengamatan di Sungai Cikaniki berkisar antara 7,3 - 7,7. Hal tersebut sesuai dengan pernyataan Andara, et.al 2014 yang menyebutkan $\mathrm{pH}$ air sungai berkisar antara $4-9$ dan kisaran $\mathrm{PH}$ yang cocok untuk organsme akuatik tidak sama tergantung pada jenis organisme. Keasaman air $(\mathrm{pH})$ juga mempengaruhi tingkat kesuburan perairan karena mempengaruhi kehidupan jasad renik. Perairan asam kurang produktif, malah dapat membunuh ikan (Gufron dan Kordi, 1997). Perubahan $\mathrm{pH}$ menjadi hal yang peka bagi sebagian besar biota akuatik. Organisme akuatik lebih menyukai $\mathrm{pH}$ mendekati $\mathrm{pH}$ netral (Siahaan et al. 2012)

\section{b. Nitrat}

Sebaran nitrat dapat dilihat pada Tabel 3. Rentang nilai sebaran nitrat adalah $0,5 \mathrm{mg} / \mathrm{L}-1,8 \mathrm{mg} / \mathrm{L}$. Di Sungai Cikaniki kandungan Nitrat masih berada dibawah baku mutu. Nitrat merupakan indikator adanya keberadaan nutrien di perairan dalam bentuk yang dapat langsung dimanfaatkan oleh tumbuhan laut seperti
Kandungan nitrat di sungai sangat penting dalam menunjang keutuhan ekosistem perairan. Hal itu terjadi karena nitrat merupakan unsur yang digunakan dalam proses fotosintesis dan merupakan unsur yang digunakan untuk pertumbuhan fitoplankton. Kadar nitrat yang banyak dalam suatu perairan dapat dikatakan bagus atau subur karena dengan nitrat maka fitoplankton akan banyak disuatu perairan sehingga akan terjadi proses fotosintesis yang menghasilkan $\mathrm{O} 2$ yang sangat dibutuhkan bagi organisme laut. Tetapi dengan kelebihan kadar nitrat dalam perairan dapat mengakibatkan dampak buruk bagi organisme. Hal itu terjadi karena dengan kadar nitrat yang tinggi maka di perairan tersebut dapat terjadi akumulasi pertumbuhan ganggang yang tak terbatas (Tarigan dan Edward, 2003).

c. Ammonia

Sebaran Amoniak di Sungai Cikaniki dapat dilihat pada Tabel 3. Rentang nilai amoniak berkisar antara $0,01 \mathrm{mg} / \mathrm{L}-0,05$ $\mathrm{mg} / \mathrm{L}$. Secara umum nilai amoniak berada diatas nilai baku mutu, Ammonia adalah suatu bentuk dari nitrogen. Tidak semua bentuk amoniak bersifat toksik. Ada dua bentuk amoniak adalah yang tidak terionisasi (NH3-) dan terionisasi (NH4+). Menurut Azizah dan Mira (2015)amonia dapat bersifat racun pada manusia jika 
jumlah yang masuk ke dalam tubuh melebihi jumlah yangdapat didetoksifikasi oleh tubuh yakni tidak lebih dari $100 \mathrm{mg} / \mathrm{kg}$ setiap hari $(33,7 \mathrm{mg}$ ion ammonium per $\mathrm{kg}$ berat badan per hari) yang dapat mempengaruhi metabolisme dengan mengubah kesetimbangan asam-basa dalam tubuh. Selain itu ammonia dengan konsentrasi 130-200 ppm dalam bentuk gas bersifat mengiritasi kulit, mata dan saluran pernafasan. Pada konsentrasi yang lebih tinggi yaitu 400-700 ppm dapat mengakibatkan kerusakan permanen akibat iritasi pada organ mata dan pernafasan (Effendi, 2003).

\section{d. Fosfat}

Nilai fosfat pada Sungai Cikaniki memiliki sebaran 0,01 - 0,04 mg/L (tabel 3).Apabila dilihat sesuai data Baku Muku, angka tersebut masih berada dibawah nilai ambang batas. Menurut hasil penelitian Sutamihardja, et al (2018) di Sungai Ciliwung nilai fosfat sudah melebihi baku mutu sehingga menyebabkan terjadinya eutrofikasi. Peningkatan nilai fosfat disebabkan oleh meningkatnya berbagai masukan beban pencemaran yang diterima badan air dan terakumulasi. Beban pencemaran dapat bersumber dari limbah domestik, limbah pertanian, limbah industri, dan peternakan (Trofisa, 2011).

Biochemical Oxygen Demand (BOD)

Kadar BOD merupakan salah satu parameter yang dapat dijadikan tolak ukur beban pencemaran suatu perairan. Pemeriksaan BOD sangat penting untuk menelusuri aliran pencemaran karena dapat menentukan beban pencemaran akibat air buangan dan mendesain sistem pembuangan secara biologis bagi air tercemar (Agnes, 2005). BOD atau Biochemical Oxygen Demand adalah suatu karakteristik yang menunjukkan jumlah oksigen terlarut yang diperlukan oleh mikroorganisme (biasanya bakteri) untuk mengurai atau mendekomposisi bahan organik dalam kondisi aerobik. Sebaran nilai BOD di Sungai Cikaniki 2,29 - 4,78 $\mathrm{mg} / \mathrm{L}$ dan keseluruhan nilai tersebut berada diatas nilai ambang batas dan seperti yang dijelaskan Gazali et al. (2013), semakin besar nilai BOD menunjukkan bahwa derajat pengotoran air limbah semakin besar. Nilai BOD tertinggi di stasiun yang merupakan saluran irigasi warga, hal tersebut dapat terjadi karena adanya penggunaan pestisida oleh warga. Nilai BOD menunjukan banyaknya pencemar organik yang ada didalam perairan sungai.

e. Chemical Oxygen Demand (COD)

Hasil pengujian sampel air kadar Chemichal Oxygen Demand (COD) di sepanjang aliran sungai Cikaniki berkisar antara 27 - $39 \mathrm{mg} / \mathrm{l}$. Kadar COD tertinggi dan juga melebihi ambang batas BMA ialah terdapat di stasiun empat yaitu $39,8 \mathrm{mg} / \mathrm{l}$. Hal ini dapat disebabkan karena terdapat saluran irigasi dan banyak penggunaan pestisida atau bahan kimia lainnya stasiun ini dan banyak sampah yang berserakan yang menyebabkan kandungan bahan kimiawi yang tinggi pada stasiun ini.

f. Dissolved Oxygen

Nilai Dissolved Oxygen sepanjang aliran sungai Cikaniki berkisar antara 8,8 sampai dengan 9,4 mg/l. Angka tersebut berada diatas Baku Mutu Air, menurut Abida, 2008 oksigen terlarut penting dalam pertumbuhan fitoplankton dalam berfotosintesis, sehingga mampu meningkatkan produktivitas primer. Cukup tingginya kadar DO pada kelima lokasi penelitian ini disebabkan proses pengambilan sampel yang tidak terlalu jauh dari permukaan sungai. Hal ini sesuai dengan yang diungkapkan (Salmin, 2005) bahwa konsentrasi oksigen terlarut tertinggi berada pada lapisan permukaan perairan. Hal ini dikarenakan adanya cahaya matahari di lapisan permukaan perairan yang diamati sehingga membantu proses fotosintesis dalam mensuplai oksigen ke perairan dan secara umum fitoplankton yang dapat melakukan fotosintesis juga paling tinggi berada pada permukaan. Konsentrasi oksigen terlarut pada umumnya mengalami penurunan dengan bertambahnya kedalaman.

g. Total Suspended Solid (TSS) 
Sebaran nilai TSS di Sepanjang aliran sungai Cikaniki adalah 10,7 - 19,7 dan angka tersebut masih dibawah nilai baku mutu air. Semakin rendah nilai TSS maka akan semakin tinggi nilai oksigen terlarut dan kecerahan. Menurut Gazali et al. (2013), zat padat tersuspensi adalah zat padat yang terapung yang dapat menimbulkan minimnya oksigen dalam air. Kandungan TSS memiliki hubungan yang erat dengan kecerahan perairan. Keberadaan padatan tersuspensi tersebut akan menghalangi penetrasi cahaya yang masuk ke dalam perairan sehingga hubungan antara TSS dan kecerahan akan menunjukkan hubungan yang berbanding terbalik.
Hasil perhitungan indeks pencemaran (Pij) menunjukkan bahwa Sungai Cikaniki masih termasuk dalam kriteria tercemar ringan (dapat dilihat pada tabel 4). Hal tersebut mungkin saja terjadi mengingat sungai mempunyai kemampuan memulihkan dirinya sendiri (self purification) dari bahan pencemar (Andara et al, 2014). Kemampuan self purification sungai terjadi karena penambahan konsentrasi oksigen terlarut dalam air yang berasal dari udara dan air hujan. Kandungan oksigen di dalam air akan menerima tambahan akibat turbulensi sehingga berlangsung perpindahan (difusi) oksigen dari udara ke air yang disebut proses reaerasi (KepMenLH 110/2003).

\section{Nilai Indeks Pencemaran}

Tabel 4. Hasil perhitungan indeks pencemaran Sungai Cikaniki Kabupaten Bogor

\begin{tabular}{llcc}
\hline No & Titik Sampling & Nilai Indeks Pencemaran & StatusMutu \\
\hline 1 & Hulu & 2,05 & cemar ringan \\
2 & Aktivitas PETI & 2,29 & cemar ringan \\
3 & Aktivitas PT. Antam & 2,22 & cemar ringan \\
4 & Irigasi & 2,35 & cemar ringan \\
5 & Hilir & 2,02 & cemar ringan \\
\hline
\end{tabular}

Secara umum stasiun yang memiliki tingkat pencemaran paling tinggi berada di stasiun 4 yang merupakan wilayah yang terdapat saluran irigasi, dan staiun 2 yang terdapat aktivitas penambang liar yang jumlahnya banyak di sepanjang aliran sungai Cikaniki. Parameter yang memiliki pengaruh paling besar dalam menentukan tingkat pencemaran di Sungai Cikaniki yang diindikasikan oleh penelitian ini adalah BOD dan COD yang merupakan parameter penanda pencemaran. Beban pencemaran bahan organik pada sungai Cikaniki ialah tinggi ditandai dengan tingginya beban pencemaran parameter BOD dan COD. Sungai Cikaniki terletak di kawasan industri dan juga lahan sepanjang aliran Sungai Cikaniki digunakan untuk pemukiman warga yang dapat menyebabkan tingginya bahan organik pada sungai ini. Menurut Agustira (2013) kegiatan industri juga memberikan masukan beban pencemaran organik ke dalam sungai tetapi nilainya masih lebih kecil bila dibandingkan dari permukiman dan pertanian.

\section{SIMPULAN}

Berdasarkan hasil penelitian dapat disimpulkan

1. Aliran Sungai Cikaniki terdapat 135 individu ikan yang ditemukan, terbagi kedalam 7 species dan memiliki keanekaragaman yang sedang.

2. Aliran Sungai Cikini berdasarkan Indeks Pencemaran mengalami cemar ringan dengan nilai $2,05-2,35$

3. Faktor Lingkungan yang paling berpengaruh terhadap pencemaran di Sungai Cikaniki adalah BOD dan COD yang nilainya melebihi Baku Mutu Air.

\section{DAFTAR PUSTAKA}

Azizah, M., M. Humairoh. 2015. Analisis Kadar Amonia (NH3) 
dalam Air Sungai Cileungsi. Jurnal Nusa Sylva. 15(1) : 47-54.

Andara D.R, Haeruddin, A. Suryanto. 2014. Kandungan Total Padatan Tersuspensi, Biochemical Oxygen Deman dan Chemical Oxygen Demand serta Indeks Pencemaran Sungai Klampiasan di Kawasan Idnustri Candi, Semarang. Diponegoro Journal of Maquares 3 (3) 177- 187.

Agustira, R. 2013. Kajian Karakteristik Kimia Air, Fisika Air dan Debit Sungai pada Kawasan DAS Padang Akibat Pembuangan Limbah Tapioka. Jurnal Online Agroekoteknologi 1 (3) : 615 - 625, Juni 2013.

Effendi, H. 2003. Telaah Kualitas Air bagi Pengelolaan Sumber Daya dan Lingkungan Perairan. Fakultas Perikanan dan Ilmu Kelautan IPB. Bogor

Gazali, Widiatmono, Rahadi, dan R, Wirosoedarmo. 2013. Evaluasi Dampak Pembuangan Limbah Cair Pabrik Kertas Terhadap Kualitas Air Sungai Klinter Kabupaten Nganjuk.Jurnal Keteknikan Pertanian Tropis dan Biosistem 1 (2) : 1-8, Juni 2013

Kottelat M, Whitten S, Kartikasari, S. Wirjoatmodjo. 1993. Freshwater fishes of Western Indonesia and Sulawesi. Jakarta: Periplus Editions.

Putri , S.P., M. Amin, E. Purwanti.Keanekaragaman

Makrofauna Pada Ekosistem Sungai Brantas dan Pengembangannya Sebagai Modul Biologi Berbasis Riset Untuk Siswa Kelas X SMA/MA. Prosiding Seminar Nasional III. 2017. Universitas Muhammadiyah Malang.

Pennak RW. Fresh water invertebrates of the United States : Protozoa to Mollusca Thirs Edition. 1989. A Wiley-Interscience Publication, John Wiley \& Son,INC.
Sheftiana U.S, A. Sarminingsih, W.D Nugraha. 2017. Penentuan Status Mutu Air Sungai Berdasarkan Metode Indeks Pencemaran Sebagai Pengendalian Kualitas Lingkungan (Studi Kasus:Sungai Gelis, Kabupaten Kudus, Jawa Tengah).Jurnal Teknik Lingkungan 6 (1).

Siahaan, R. 2011. Kualitas Air Sungai Cisadane Jawa Barat Banten. Jurnal Ilmiah Sains 11 (2) : 268 - 273, Oktober 2011.

Sutamihardja, RTM, M. Azizah., Y. Hardini. 2018. Studi Dinamika Senyawa Fosfat dalam Kualitas Air Sungai Ciliwung Hulu Kota Bogor. Jurnal Sains Natural. 8 (1):43 - 49.

Trofisa, D. 2011. Kajian Beban Pencemaran dan Daya Tampung Pencemaran Sungai Ciliwung di Segmen Kota Bogor . Fakultas Kehutanan, Institut Pertanian Bogor, Bogor.

Wahyuni , T.T.,A. Zakaria. 2018. Keanekaragaman Ikan di Sungai Luk Ulo Kabupaten Kebumen. Biosfera. 35 (1): 23 - 28 DOI: 10.20884/1.mib.2018.35.1.592 